\title{
Environmental Stress Effect on Animal Reproduction
}

\author{
Córdova-Izquierdo Alejandro1, Villa-Mancera Abel2, Olivares Pérez Jaime³, \\ Sánchez-Aparicio Pedro ${ }^{4,5}$ \\ ${ }^{1}$ Departamento de Producción Agrícola y Animal, Universidad Autónoma Metropolitana Unidad Xochimilco, \\ México DF, México \\ ${ }^{2}$ Laboratorio de Genética y Reproducción, Facultad de Medicina Veterinaria y Zootecnia, Benemérita \\ Universidad Autónoma de Puebla, México DF, México \\ ${ }^{3}$ Universidad Autónoma de Guerrero-Unidad Académica de Medicina Veterinaria y Zootecnia, México DF, \\ México \\ ${ }^{4}$ Facultad de Medicina Veterinaria y Zootecnia, Universidad Autónoma del Estado de México, Toluca, \\ México \\ ${ }^{5}$ Bioterio del Hospital Veterinario para Pequeñas Especies UAEM, Toluca, México \\ Email: acordova@correo.xoc.uam.mx
}

Received 23 February 2014; revised 27 March 2014; accepted 4 April 2014

Copyright (C) 2014 by authors and Scientific Research Publishing Inc.

This work is licensed under the Creative Commons Attribution International License (CC BY). http://creativecommons.org/licenses/by/4.0/

(c) (i) Open Access

\section{Abstract}

The aim of this review is to present some aspects of environmental stress effect on reproduction of farm animals. It describes the following: neuroendocrinology of stress, types of stress, stress characteristics in the reproductive process and recommendations for control environmental stress. Stress is the result of confinement and an ambitious vision and uncaring by the man, who is in the interest of improving production, has participated unconsciously, by manipulating animal production in its way, even trying to tame new species, impossible to adapt to our environment healthy. At present, it has been concluded that stress is one of the environmental factors that affect handling and decrease the production of livestock, it is considered that the main factor which should be controlled in units animal production, since it is closely related to pathogens and infectious agents that may try to the health of animals. Finally, some recommendations are outlined to lessen stress for heat, by handling and by feeding.

\section{Keywords}

Environmental Stress; Animal Reproduction; Caloric Stress; Caloric Handling; Caloric Nutrition 


\section{Introduction}

At present, the need to produce more efficiently, the need to improve reproductive and productive parameters so that new technologies have been adopted which are becoming more sophisticated, all in order to increase the production in animals.

Despite the advances in technology are applied to animal production, few producers or farmers who have shown concern for improving the general environmental conditions of the animal production units, not realizing that these conditions are largely, are responsible for the health of animals, altering thereof and being significantly impacting on the presence of such problems reproductive and productive, significantly increasing production costs.

Stress is the result of confinement and an ambitious vision and uncaring by the man, who is in the interest of improving production, has participated unconsciously, by manipulating animal production in its way, even trying to tame new species, impossible to adapt to our environment healthy.

At present, it has been concluded that stress is one of the environmental factors that affect handling and decrease the production of livestock, it is considered that the main factor which should be controlled in units animal production, since it is closely related to pathogens and infectious agents that may try to the health of animals.

The man plays a very important role in creating the stress. It can provide the means to alleviate, remove or modify any potential stressor [1]. Some of the criteria that have been used to indicate the presence of stress in animals are the thyroid hormones such as corticosteroids plasma or urinary catecholamine's and/or its metabolites, lactic acid, serum enzymes, blood glucose, alterations in the frequency respiratory or cardiac and somatic cell count in milk.

\section{Stress Neuroendocrinology}

Mammals, respond to environmental changes by adaptation mechanisms, regulated by the release of hormones such as: Adrenocorticotropin (ACTH), glucocorticoids (GH) and catecholamine (CA), the amount of release depends on the type and intensity of the stress that comes along.

Under stress, there is a negative feedback effect of progesterone on luteinizing hormone (LH) increasing the first. Are elevated cortisol levels with subsequent depression, there are changes in the release of LH. The level of prostaglandin F2 alpha (PGF2 $\infty$ ) and ACTH increase. The levels of epinephrine and norepinephrine, also increase [1]. All this adversely affects reproductive function in mammals [2].

\section{Types of Stress}

\subsection{Caloric}

Solar radiation, wind speed, air temperature and humidity are all factors which are concerned with the presentation of heat stress. An early reproductive responses to heat stress are the decrease in the intensity of estrus and consequently low fertility [3]. It is known that mammalian females are more sensitive to heat stress, during the 12 days before estrus, increasing this sensitivity on day 2 before [4].

Studies by [2] found that the absence of high temperatures cause libido, as well as affecting the quantity and quality of semen. They also reduce heat filing and when present, are less intense and of shorter duration. If the female is pregnant, the possibility of embryonic mortality is high, factors lead to a decrease in the fertility of domestic mammalian females [5].

Recent studies conducted by [6], mentioned for the first time, evidence of the delayed effect of heat stress on follicular steroidogenesis revealed that exposure of female domestic heat stress led to a decrease in steroidogenesis, 20 and 26 days later, in mid-sized preovulatory follicles. Furthermore, the theca cells more susceptible found that granulose cells and they expressed low estrogen production in medium-sized follicles and low viability in preovulatory follicles. In terms of production of steroids, theca cells appeared to be consistently susceptible to heat stress and expressed transport effects on androgen production in both types of follicles.

When the body temperature exceeds $40^{\circ} \mathrm{C}$, the developed follicles can suffer severe damage and become nonviable [7], are secreted higher levels of progesterone, which inhibits the release of LH during estrus, interrupting the process of Ovulation [8].

A study by [9] has revealed that heat stress reduces dominant follicle size of the first and second follicular wave. In another study, [9], indicate that exposing domestic female mammals during heat stress is altered folli- 
cular dynamics and lowers the follicular dominance in the next cycle. In 1997, Wolfensohn et al., Argued that the preovulatory follicle is a key component in the reproductive system and the deterioration of their function during heat stress may trigger other reproductive effects, such as distortion in gonadotropin secretion, underdevelopment of the body luteum and embryo, resulting in a low fertility.

Studies by under in vitro conditions, suggesting that exposure of pregnant domestic females at high ambient temperatures and humidity, which often occur during the summer months, can disrupt the balance between the biochemical and endometrial factors responsible for the maintenance of pregnancy. [9] indicated that the lipid composition of membranes of oocytes are more deteriorated in summer than in winter. An important aspect to counteract the effect of heat stress on the quality of the oocyte and embryo development is the potential use of antioxidants to increase the strength of both the oocyte and embryo.

In 1994, [10] found that the cooled for 2 to 3 to 5 to 6 days after the pregnancy, pregnancy rates improved as compared with females under heat stress. Moreover, [8] found that thyroxine and triiodothyroxine can reduce heat stress.

It has been shown that during periods of severe heat stress, only $10 \%$ to $20 \%$ of inseminations can result in normal pregnancies [7]. In Israel, conception rates during the winter months reach more than 50\%, while during the summer can lose up to $20 \%$ [11]. In cattle, it has been found that the Jersey breed is more tolerant to heat stress that Holstein.

Work performed in the United States, indicate that Holstein and Jersey cows set in hot, express signs of estrus for only 12 to 13 hours, which means a difference of 5 - 6 hours less than the normal duration of estrus animals warm places [11].

In the 2000 [13] indicated that dairy cows with black layer absorb more heat from sunlight, cows of white layer. In this regard, it is known that the temperature from which affected reproductive efficiency in cattle, is in a range ranging from $21.1^{\circ} \mathrm{C}$ to $32.2^{\circ} \mathrm{C}$, so that indicated [13], that the cows need to be cooled as much as possible throughout the summer, in order to raise fertility.

In other studies in Florida, by [14] showed that in summer with heat and humidity conditions, pregnancy rates are down to $10 \%$.

The best way to control the effects of heat stress are: 1) physical modification of the environment, 2) breeding races less sensitive to heat stress and, 3) good nutritional management [11].

\subsection{Nutrition}

In 1998, Zapiola said that in cattle, stress during transportation, has a detrimental effect on the physiology of the animal that the stress caused by lack of food and drink, for a period of equal length, which is because the blood flow is diverted from the internal organs, to the peripheral tissues in an attempt to reduce the body temperature by increasing heat losses. This mechanism leads to a reduction of blood flow, aimed at internal organs such as the uterus, fallopian tubes and ovaries, decreased blood supply to these organs also implies low nutrient availability and therefore low functional capacity [12].

Studies by [8], reflected the corpus luteum of nutrition-stressed females, is lighter and also indicated by chemical constituents of allantoic fluid, the underfed female embryos, degenerate.

Females consume less food during warm seasons, consequently, there may be insufficient nutrients are available, after the production of milk and therefore the ovaries do not function during the first 6 weeks of lactation [14].

Vitamin E may decrease moderately, the effects of heat stress during hot months, does not necessarily increase fertility [10]. A proactive factor could be the adequate food supply in quantity and quality, which have direct effects on reproduction and on the alterations caused by the indirect effects of nutritional stress [14].

\subsection{By Handling}

The interactions between employees and animals influence the response of cattle to stress management known as [14].

In 2000, [13], indicated that the way to handle livestock, animals may produce an unnecessary handling stress, which may affect the biological mechanisms of reproduction and the immune response. On the other hand, electrical bites, immobilization and other stress factors management weaken the female reproductive functioning.

There are many driving situations can cause stress seriously affecting the reproductive process of the species, 
such as excessive mobilization of inseminated females before, the use of aggressive or driving the separation of animals, mobilization of animals on the sleeve of management for different purposes, etc. [14].

The time when stress management, represents greater adverse effects on reproduction, it is just no time to estrus [13].

The temperament of cattle can be classified as follows: 1) stand still while subject, 2) is restless, 3) shaken vigorously driving sleeve and 4) shakes violently management sleeve and tries to escape. Overall, in cattle, the Bos indicus have a more aggressive and nervous temperament than Bos taurus [14].

\section{Characteristics of Stress in Reproductive Process}

In 2000 [13] indicated that the process of reproduction is an important physiological system for the development of species, linked to stress, that [1] has classified into two groups: environmental stress and handling. Environmental stress includes room temperature, cold and/or hot and cold, wind and moisture. The stress management includes animal density, to handling procedures, the flow of animals, to the interaction between animals of the same or different species and the existing social condition, as nonspecific psychological distress, noise, physical trauma, etc. The combination of both types of stress, act as stressors, which compromises the homeostasis of the animal.

Moreover, [2] mentioned the following types of stress: physical, which includes the transport of animals and physical damage, psychological, which provides for the isolation of animals, physiological, in which considered to hypoglycemia and changes in blood pressure, all aspects related to the reproductive process of mammals.

Cattle, is one of the most adaptable and homeocinéticos have mechanisms to maintain body functions at the expense of critical changes in other physiological functions, such as reproduction, so that the reproductive function is determined largely by the environment [11].

Constant maintenance of a normal body temperature is known as homeotermia and is vital to the functioning of the brain tissue. In cattle, the normal diurnal variation in body temperature should be from 0.6 to $1.2^{\circ} \mathrm{C}$. A further increase to $1.2^{\circ} \mathrm{C}$ is a sign of illness or poor adaptation to temperature elevation. This temperature range is known as a zone of comfort, varies according to the species and animal breeds. When animals have a body temperature below or above their level of comfort, decreases or increases metabolic rate than normal, appearing in imbalance in animal welfare. Heat or body temperature can be eliminated by the following mechanisms: radiation, conduction, convection and evaporation [11].

\subsection{In the Male}

\section{Semen Quality}

Environmental stress can cause low sperm quality, which is closely related to low fertility in females, probably due to a combination of low fertilization rates and increased embryonic mortality [1] [14].

Direct exposure of the testis at high temperatures, causes changes in certain critical stages of spermatogenic cycle, which is also directly related to the quality of the ejaculate.

Recent studies conducted by [13] suggested that the effect of stress on sperm quality, can be improved by implementation of the seminal freezing technology, however, the uterus of female stress may represent heat to sperm.

\subsection{In the Female}

Sexual behavior and fertility rate are the main indicators of the mammalian female reproduction that are negatively affected by environmental stress. So that the programs undertaken in order to increase the fertility of domestic females, are less successful in hot weather than in temperate [11].

A temperature increase of $0.5^{\circ} \mathrm{C}$ uterine during hot days, caused a decrease in the rate of fertilization. In cattle, heifers exposure to $32^{\circ} \mathrm{C}$ for 72 hours after insemination, inhibit embryonic development, however, it is known that $48 \%$ of the females held $21^{\circ} \mathrm{C}$, can become pregnant without any problem. If heat stress is presented after 10 days after the service, fertility is not affected.

\subsubsection{On Fertility}

Fertility in lactating cows, varies by season. In the winter, decreases about $50 \%, 20 \%$ in the summer and fall is lower than in the winter. A few years earlier, Gilad et al., (1993) reported that conception rates in Israel fell 
from $52 \%$ in winter to $24 \%$ in the summer.

In summer, 80\% of estrus may be undetectable [14]. Also indicated, Ryan et al. (1992) when the rectal temperature of the animals increased from $38.5^{\circ} \mathrm{C}$ to $40^{\circ} \mathrm{C}$ in 72 hours after insemination service, pregnancy rates can decrease up to $50 \%$.

Heifers and cows studies have indicated that the decline in oocyte quality in the early postpartum period is associated with negative energy balance and low body condition of the animals, which is expressed in developing embryos increased and abnormal having embryos resulting in loss of the hottest months of the year [13].

\subsubsection{On Embryos}

Several studies [10] [14] have indicated that in cattle, embryonic development is highly sensitive to high temperatures, in the top three to 11 days after service; acquiring more heat tolerance as the gestation period progresses. It is known that the embryos obtained by in vitro fertilization (IVF) are more susceptible to heat stress than those obtained under natural conditions. In this regard, [14] indicated that the greatest loss of bovine embryos from IVF, occur before 42 days, when females are under heat stress.

\section{Recommendations for Controlling Environmental Stress}

\subsection{For Heat}

- Provide a ventilation system that controls body temperature.

- Implement water sprinklers.

- Animal protection against solar radiation, directly and indirectly, through shadows or appropriate ceilings.

- Provide shade in feeding and drinking, to increase feed intake in animals with heat stress.

- Provide water sprays.

- Provide animals, spray baths, in the hottest part of the day.

- Try to have animals with white fur, as they are the most easily absorb heat and therefore are less sensitive to heat stress.

- Develop genetically adapted in animals, as they may be less sensitive to heat stress.

- Implementation of frozen embryos.

- Insemination with frozen semen in less hot time.

\subsection{By Handling}

- Provide free areas in the Production Unit and shaded.

- Provide the required area per animal, for comfort.

- Bathing females before service and 3 to 5 days.

- Breed or service in less hot periods.

- Implement estrus synchronization programs, to schedule inseminations or services.

- Do not isolate females long before artificial insemination or service.

\subsection{By Feeding}

- Balancing diets properly, providing the energy needed to offset declining intake presented.

- Reduce your intake of fiber and protein and increase energy.

\section{Conclusion}

The effects of the environment on the reproduction of farm animals, negatively affect reproductive performance in both females and males, in females, on the percentage of fertility, declining oocyte quality and therefore the quality of the embryo; in males negatively affect the quantity and quality of sperm. Therefore, it is recommended to follow the guidelines described in this paper to reduce the effect of environmental stress on reproduction of farm animals.

\section{References}

[1] Coubrough, R.I. (1985) Stress and Fertility. A Review. Onderstepoort Journal of Veterinary Research, 52, $153-156$. 
[2] Dobson, H. and Smith, R.F. (1995) Stress and Reproduction in Farm Animals. Journal of Reproduction and Fertility. Supplement, 49, 451-461.

[3] Ullah, G., Fuquay, J.W., Keawkhong, T., Clark, B.L., Pogue, D.E. and Murphey, E.J. (1996) Effect of GonadotropinReleasing Hormone at Estrus on Subsequent Luteal Function and Fertility in Lactating Holsteins during Heat Stress. Journal of Dairy Science, 79, 1950-1953. http://dx.doi.org/10.3168/jds.S0022-0302(96)76565-7

[4] Gilad, E., Meidan, R., Berman, A., Graber, Y. and Wolfenson, D. (1993) Effect of Heat Stress on Tonic and GnRHInduced Gonadotrophin Secretion in Relation to Concentration of Oestradiol in Plasma of Cyclic Cows. Journal of Reproduction and Fertility, 99, 315-321. http://dx.doi.org/10.1530/jrf.0.0990315

[5] Roth, Z., Arav, A., Bor, A., Zeron, Y., Braw-Tal, R. and Wolfenson, D. (2001) Improvement of Quality of Oocytes Collected in the Autumn by Enhanced Removal of Impaired Follicles from Previously Heat-Stressed Cows. Reproduction, 122, 737-744. http://dx.doi.org/10.1530/rep.0.1220737

[6] Lee, C.N. (1993) Environmental Stress Effects on Bovine Reproduction. Veterinary Clinics of North America: Food Animal Practice, 9, 263-273.

[7] Roth, Z., Meidan, R., Braw-Tal, R. and Wolfenson, D. (2000) Immediate and Delayed Effects of Heat Stress on Follicular Development and Its Association with Plasma FSH and Inhibin Concentration in Cows. Journal of Reproduction and Infertility, 120, 83-90.

[8] Ealy, A.D., Arechiga, E.F., Bray, D.R., Risco, C.A. and Hansen, P.J. (1994) Effectiveness of Short-Term Cooling and Vitamin E for Alleviation of Infertility Induced by Heat Stress in Dairy Cows. Journal of Dairy Science, 77, 36013607. http://dx.doi.org/10.3168/jds.S0022-0302(94)77304-5

[9] Wolfenson, D., Lew, B.J., Thatcher, W.W., Graber, Y. and Meidan, R. (1997) Seasonal and Acute Heat Stress Effects on Steroid Production by Dominant Follicles in Cows. Animal Reproduction Science, 47, 9-19. http://dx.doi.org/10.1016/S0378-4320(96)01638-7

[10] Ambrose, J.D., Drost, M., Monson, R.L., Uutledge, J.J., Leibfried-Rutredge, M.L., Thatcher, M.-J., Kassa, T., Binelli, M., Hansen, P.J., Chenoweth, P.J. and Thatcher, W.W. (1999) Efficacy of Timed Embryo Transfer with Fresh and Frozen in Vitro Produced Embryos to Increase Pregnancy Rates in Heat-Stresed Dairy Cattle. Journal of Dairy Science, 82, 2369-2376. http://dx.doi.org/10.3168/jds.S0022-0302(99)75487-1

[11] Dobson, H., Tebble, J.E., Smith, R.F. and Ward, W.R. (2001) Is Stress Really All That Important? Theriogenology, 55, 65-73. http://dx.doi.org/10.1016/S0093-691X(00)00446-5

[12] Zapiola, M. (1998) La reducción del estrés del manejo mejora la productividad y el bienestar animal. http://www.grandin.com/spanish/reduccion.estres.manejo.html

[13] Dobson, H. and Smith, R.F. (2000) What Is Stress, and How Does It Affect Reproduction? Animal Reproduction Science, 2, 743-752. http://dx.doi.org/10.1016/S0378-4320(00)00080-4

[14] Rutledge, J.J. (2001) Use of Embryo Transfer and IVF to Bypass Effects of Heat Stress. Theriogenology, 55, $105-111$. http://dx.doi.org/10.1016/S0093-691X(00)00449-0 